\title{
Prevalence of Middle Mesial Canals and Isthmi in Mandibular Molars Using Cone Beam Computed Tomography
}

\author{
Attique ur Rehman ${ }^{1}$ \\ Saqib Naeem Siddique ${ }^{2}$ \\ Saba Rehman ${ }^{3}$ \\ Mehwish Munawar ${ }^{4}$ \\ Haroon Asghar Ginai ${ }^{5}$
}

\author{
BDS, FCPS \\ BDS, FCPS \\ BDS \\ BDS, FCPS \\ BDS, FCPS
}

OBJECTIVE: The purpose of this study was to investigate the prevalence and configuration of Middle Mesial Canals (MMC) and isthmi in mandibular molars in Pakistani population using Cone Beam Computed Tomography (CBCT).

METHODOLOGY: Sixty CBCTs of patients were selected randomly from database of University College of Dentistry, Lahore. First and second permanent mandibular molars without evidence of previous endodontic treatment, full coverage restoration or root resorption were evaluated for the number of roots, canals and the presence and configuration of MMC and isthmi. The age and gender of patients were also recorded. SPSS was used for statistical analysis using chi-square test. Significance level was set at $5 \%(\mathrm{P}<0.05)$.

RESULTS: Out of 189 mandibular molars, MMCs were found in 9 and isthmi in 62 teeth. No statistical association was found between the presence of MMC and age, gender, side or tooth type. Significantly more isthmi were found in second molars, females and younger patients, $\mathrm{P}<0.05$.

CONCLUSION: MMC and isthmi in mesial roots of mandibular molars are not unusual findings in our population and CBCT can be a valuable tool for their detection.

KEYWORDS: Cone-Beam computed tomography, isthmus, mandibular molar, middle mesial canal, root canal therapy HOW TO CITE: Rehman UA, Siddique SN, Rehman S, Munawar M, Ginai HA. Prevalence of middle mesial canals and isthmi in mandibular molars using cone beam computed tomography. J Pak Dent Assoc 2020;29(3):114-119.

DOI: https://doi.org/10.25301/JPDA.293.114

Received: 17 December 2019, Accepted: 27 April 2020

\section{INTRODUCTION}

$\mathrm{N}$ on-surgical endodontic treatment generally has a high success rate. Anatomical variations such as missed canals and isthmi are one of the main causes of endodontic treatment failure. ${ }^{1}$ Untouched areas of canals contain necrotic debris and bacterial contents, and have been linked with the presence of apical periodontitis. ${ }^{2}$ Isthmi which are narrow ribbon like communications between canals, are difficult to completely debride by current chemomechanical preparation techniques. ${ }^{3}$ Identification and treatment of the entire endodontic space is vital for

1. Assistant Professor, Department of Operative Dentistry, Azra Naheed Dental College, Lahore.

2. Assistant Professor, Department of Operative Dentistry, University College of Dentistry, University of Lahore, Lahore, Pakistan.

3. Demonstrator, Azra Naheed Dental College, Lahore.

4. Assistant Professor, Operative Dentistry, University College of Dentistry, University of Lahore, Lahore, Pakistan.

5. Assistant Professor, Department of Operative Dentistry, Superior University, Lahore

Corresponding author: "Dr. Attique ur Rehman" < attique_1@ hotmail.com > successful endodontics.

The root canal anatomy can be studied in vitro on extracted teeth using sectioning, diaphonization, plastic dye, micro CT and other techniques. ${ }^{4}$ However, the results obtained from extracted teeth may not be truly applicable on clinically restorable teeth that are to be endodontically treated. Complications like calcifications and sclerosed canals may give different results. ${ }^{5}$ In vivo methods can therefore give more representative information. Canals can be identified during treatment with the help of various aids like magnification, hand instruments, dye application, fiber-optic illumination, champagne bubble test and ultrasonics. ${ }^{4}$ Radiographs provide a non-invasive in vivo method of detecting canals and can be applied to healthy intact teeth. Conventional periapical radiographs provide limited information in two dimensions, with overlap of structures in the bucco-lingual direction. Cone beam computed tomography (CBCT) has proved to be useful for investigating complex root canal morphology as it enables visualization 
in all three dimensions. ${ }^{6}$

The periapical radiograph is recommended for routine preoperative endodontic evaluation. If there is a need for additional information, and benefits outweigh the risks, $\mathrm{CBCT}$ can be considered on an individual basis. A guideline issued jointly by American Association of Endodontics (AAE) and American Association of Oral \& Maxillofacial Radiology (AAOMR) proposed that teeth with potential for extra canals such as mandibular molars should be evaluated with a limited field of view (FOV) $\mathrm{CBCT}^{7}$

The utilization of CBCT for diagnosing complex endodontic anatomy varies geographically and with the level of qualification of dentists. ${ }^{8}$ A survey reported that when missed canals were suspected, dental practitioners ordered CBCT in only $25 \%$ of cases. ${ }^{8}$ Some studies report that the treatment plan formulated was quite different if preoperative assessment was done with CBCT as compared to when it was done without it, while other studies report insignificant influence. ${ }^{10,11}$

Mandibular molars are one of the most frequently endodontically treated teeth. ${ }^{12}$ The classical anatomy of mandibular molars is described as having two roots, one mesial and one distal. The mesial roots typically contain a mesiobuccal (MB) and a mesiolingual (ML) canal. ${ }^{5}$ At times they may have an extra canal in the middle of the two main canals, termed middle mesial canal (MMC).

It was found that the unaided eye could detect only between $29 \%$ to $46 \%$ of MMC that were visible in CBCT. ${ }^{13}$ One study found that even with angled periapical radiographs, endodontists missed at least one extra canal in every 4 out of 10 teeth when further assessed by CBCT. ${ }^{14}$ In the presence of MMC and isthmus, root canal preparation and filling can be more difficult. Similarly, in surgical endodontic treatment, root end preparation and retrograde filling can be more challenging because of the complex morphology of mesial roots. ${ }^{15}$

The reported incidence of MMC in mandibular molars varies with the population being studied. Previously it was reported as between 1-15\% with slightly less incidence in mandibular second molars compared to mandibular first molars. ${ }^{16}$ A recent systematic review that included 41 studies from different populations quoted a range of 0.26 to $53.8 \% .^{5,17}$ There can also be a communication or 'isthmus' between the mesial canals. The isthmus can be present in the entire root length, or confined to some part of it. A systematic review found the average prevalence of isthmus in mesial roots be 55\%. ${ }^{5}$ Very few studies report the statistics in Pakistani population. The presence of MMC in mandibular first molars was reported in only one in vitro study, and found one MMC in 30 teeth. ${ }^{18}$ Another in vitro study that used clearing technique reported no middle mesial canal in
123 mandibular first molars. ${ }^{19}$ The presence of MMC in mandibular second molar was reported in only one case report. ${ }^{20}$ No CBCT study has been conducted in Pakistani population to our knowledge.

This study is being conducted to determine the prevalence of MMC and isthmi in mandibular first and second molars using CBCT in our population.

\section{METHODOLOGY}

It was a retrospective study conducted at the University College of Dentistry, Lahore. The Sample size was calculated to be one hundred and forty-nine teeth using OpenEpi online calculator with expected prevalence of $10.8 \%$, confidence level of $95 \%$ and confidence limit at $5 \% .{ }^{15}$ It was later increased to one hundred and eighty-nine teeth. Sixty randomly selected medium field of view CBCT images from database of Oral \& Maxillofacial Radiology department taken between February 2017 and January 2019 were included in the study. All images were recorded using Planmeca ProMax 3D Max (Planmeca, Helsinki, Finland) CBCT unit, with voxel size of $200 \mathrm{um}$ and exposure settings at $90 \mathrm{kVp}$ and $5 \mathrm{~mA}$. Images were viewed using Planmeca Romexis Viewer version 5.2.1.R on Acer Aspire E571 laptop running Microsoft Windows 10 Pro operating system with a 15-inches light emitting diode screen at $1366 \times 768$ pixels resolution in a dimly lit environment. Images were adjusted using the built-in tools for optimum viewing and evaluated in all 3 planes slice by slice, simultaneously by 3 assessors. The opinion of majority observers was considered if there was any disagreement regarding the interpretation of individual CBCT images.

Permanent 1st and 2nd (either or both, whichever present) mandibular molars with no evidence of endodontic treatment or root resorption seen in CBCTs without any imaging artefact in the area of concern were included. Presence and configuration of isthmi and $\mathrm{MMC}$ in the mesial roots was recorded. MMC was noted when a well-defined round or oval radiolucency between the MB canal and ML canal was observed in the axial view, irrespective of the presence of an isthmus. Isthmus was noted to be present when a narrow ribbon or fin like connection existed between the MB canal and ML canal. If MMC was located in the axial view, its configuration was further evaluated in the coronal view in the similar sequential manner, after correctly orienting the root in sagittal and axial views. Canal origin (or orifice), apical extension, and fusion with adjacent canals was also noted. MMC and isthmi were later classified according to their start and end locations. Sex and age of patients was noted, the age was recorded in one of 4 groups; $<20,21-40,40-60$ and $>60$. Data was analyzed using 

molars using CBCT

Statistical Package for Social Sciences, version 24 (SPSS Inc, Chicago, IL). Chi-squared test was used to compare the presence and prevalence of MMC and isthmi, as well as their association with age and sex. Significance level was set at $5 \%(\mathrm{P}<0.05)$.

\section{RESULTS}

CBCTs of fifty one patients were evaluated ( $45 \%$ males and $55 \%$ females, mean age $=31$ years). A total of one hundred and eighty-nine teeth were evaluated out of which ninety-four were mandibular first molars and ninety-five were mandibular second molars. MMC were found in nine $(4.8 \%)$ teeth (Figure-1 \& 2). In first molars, the prevalence

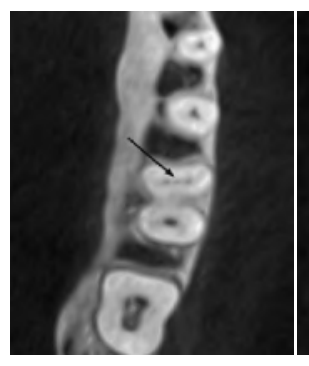

Fiqure: 1

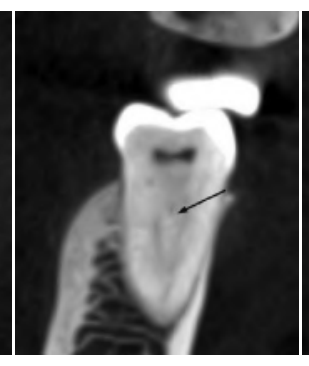

Fiqure: 2

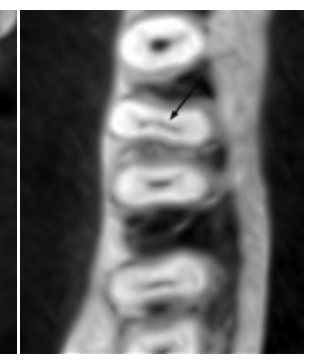

Fiqure: 3
Table 1: Distribution of middle mesial canals according to molar type, side, gender and age

\begin{tabular}{|c|c|c|c|c|c|}
\hline \multirow[b]{2}{*}{ Molar } & \multicolumn{5}{|c|}{ MM canal } \\
\hline & \multicolumn{2}{|l|}{ 1st molars } & 2nd molars & TOTAL & \\
\hline Type & \multicolumn{2}{|l|}{$6(6.4 \%)$} & $3(3.2 \%)$ & $9(4.8 \%)$ & $>0.05$ \\
\hline \multirow[t]{2}{*}{ Side } & \multicolumn{2}{|l|}{ Right } & Left & & $P$ value \\
\hline & \multicolumn{2}{|l|}{$2(1.1 \%)$} & $7(3.7 \%)$ & $9(4.8 \%)$ & $>0.05$ \\
\hline \multirow[t]{2}{*}{ Gender } & \multicolumn{2}{|l|}{ Male } & Female & & $P$ value \\
\hline & \multicolumn{2}{|l|}{$4(2.1 \%)$} & $5(2.6 \%)$ & $9(4.8 \%)$ & $>0.05$ \\
\hline \multirow[t]{2}{*}{ Age } & 20 or less & $20-40$ & 40 or more & & $P$ value \\
\hline & $2(1.1 \%)$ & $5(2.6 \%)$ & $2(1.1 \%)$ & $9(4.8 \%)$ & $>0.05$ \\
\hline
\end{tabular}

of MMC was $6.4 \%$, while in second molars it was $3.2 \%$, $\mathrm{P}>0.05$ (Table-1). No significant difference was found when data was stratified for side, gender and age (Table-1). Isthmi were found in sixty-two (32.8\%) teeth (Figure-3), with prevalence of $22.3 \%$ in first molar and $43.2 \%$ in second molar, $\mathrm{P}<0.05$ (Table-2). Significantly greater incidence of isthmi was found in younger age and in females, $\mathrm{P}<0.05$, while there was no significant difference between the two sides (Table-2). The distribution of MMC and isthmi according to their presence in different views is listed in Table-3. The distribution of MMC and isthmi according to their start and end is listed in Table-4. The orifices of
Table 2: Distribution of isthmi according to molar type, side, gender and age

\begin{tabular}{|c|c|c|c|c|c|}
\hline & \multicolumn{4}{|c|}{ Isthmus } & \\
\hline Molar & \multicolumn{2}{|l|}{ 1st molars } & 2nd molars & TOTAL & P value \\
\hline Type & \multicolumn{2}{|l|}{$21(11.1 \%)$} & $41(21.7 \%)$ & $62(32.8 \%)$ & $<0.05$ \\
\hline \multirow[t]{2}{*}{ Side } & \multicolumn{2}{|l|}{ Right } & Left & & $P$ value \\
\hline & \multicolumn{2}{|l|}{$30(15.9 \%)$} & $32(16.9 \%)$ & $62(32.8 \%)$ & $>0.05$ \\
\hline \multirow[t]{2}{*}{ Gender } & \multicolumn{2}{|l|}{ Male } & Female & & $P$ value \\
\hline & \multicolumn{2}{|l|}{$21(11.1 \%)$} & $41(21.7 \%)$ & $62(32.8 \%)$ & $<0.05$ \\
\hline \multirow[t]{2}{*}{ Age } & 20 or less & $20-40$ & 40 or more & & $P$ value \\
\hline & $23(12.2 \%)$ & $32(16.9 \%)$ & $7(3.7 \%)$ & $62(32.8 \%)$ & $<0.05$ \\
\hline
\end{tabular}

Table 3: Distribution of middle mesial canals and isthmus according to their incidence in different sections of the root

\begin{tabular}{|l|l|c|}
\hline & MM canal & \multicolumn{1}{|c|}{ Isthmus } \\
\hline Cervical 3rd & $9(4.8 \%)$ & $56(29.6 \%)$ \\
\hline Middle 3rd & $4(2.1 \%)$ & $35(18.5 \%)$ \\
\hline Apical 3rd & $0(0 \%)$ & $32(16.9 \%)$ \\
\hline
\end{tabular}

Table 4: Distribution of MM canals and isthmus according to their start and end

\begin{tabular}{|l|r|r|}
\hline & MM canal & \multicolumn{1}{|c|}{ Isthmus } \\
\hline Cervical 3 $^{\text {rd }}$ only & $5(2.6 \%)$ & $18(9.5 \%)$ \\
\hline${\text { Cervical \& middle } 3^{\text {rd }}}^{\text {rd }}$ & $4(2.1 \%)$ & $12(6.3 \%)$ \\
\hline Cervical to apical 3 $^{\text {rd }}$ & $0(0 \%)$ & $21(11.1 \%)$ \\
\hline Middle 3 $^{\text {rd }}$ only & $0(0 \%)$ & $0(0 \%)$ \\
\hline${\text { Middle \& apical } 3^{\text {rd }}}^{\text {rd }}$ & $0(0 \%)$ & $2(1.1 \%)$ \\
\hline Cervical \& apical $^{\text {Apical }}{ }^{\text {rd }}$ only & $0(0 \%)$ & $5(2.6 \%)$ \\
\hline Total & $0(0 \%)$ & $4(2.1 \%)$ \\
\hline
\end{tabular}

Table 5: Distribution of orifices of the MMCs

\begin{tabular}{|l|l|}
\hline \multicolumn{1}{|c|}{ Orifice } & \multicolumn{1}{c|}{ Number } \\
\hline Separate & $\mathbf{5 ( 5 5 \% )}$ \\
\hline Shared with ML & $\mathbf{4 ( 4 4 \% )}$ \\
\hline Total & $\mathbf{9 ( 1 0 0 \% )}$ \\
\hline
\end{tabular}

5 MMCs (55\%) were separate, the rest were shared (45\%) with ML canal (Table-5). Five MMCs fused during their course with the ML canal, two fused with MB canal and two ended blindly (Table-6). Neither any of the middle mesial canals exited from separate apical foramina, nor were observed in the roots' apical third. Presence of isthmus in 
Table 6: Course of the MMCs

\begin{tabular}{|l|l|}
\hline \multicolumn{1}{|c|}{ Course } & Number \\
\hline Fused with ML canal & 5 \\
\hline Fused with MB canal & 2 \\
\hline Blind termination & 2 \\
\hline Total & 9 \\
\hline
\end{tabular}

Table 7: Prevalence of isthmus in apical area and number of canals according to molar type

\begin{tabular}{|l|l|l|l|l|}
\hline \multicolumn{2}{|c|}{} & 1st molar & 2nd molar & P value \\
\hline \multicolumn{2}{|c|}{ Isthmus in apical area } & $9(9.6 \%)$ & $23(24.2 \%)$ & $<0.05$ \\
\hline Number of Canals & 3 or less & $52(27.5 \%)$ & $87(46.0 \%)$ & $<0.05$ \\
\cline { 2 - 5 } & 4 or more & $42(22.2 \%)$ & $8(4.2 \%)$ & \\
\hline
\end{tabular}

apical area was significantly greater in second molars, $\mathrm{P}<0.05$, while the total number of canals in a tooth were found to be greater in first molars as compared to second molars, $\mathrm{P}<0.05$ (Table-7).

\section{DISCUSSION}

The incidence of MM canals was lower in present study (4.8\%) compared to other CBCT studies by Tahmasbi et al. $(16.4 \%)$ and Baugh eta al. (10.8\%). ${ }^{15,21}$ The reported prevalence of MMC differs with the ethnicity of the studied population, geographic location and study methodology. ${ }^{17}$ Another reason for the difference could be the finer voxel size of CBCT in the other studies $(76 \mu \mathrm{m}$ in Tahmasbi et al.'s study and $160 \mu \mathrm{m}$ in Baugh et al.'s study) compared to present study $(200 \mu \mathrm{m})$. A retrospective in vivo study conducted by Nosrat et al. found 20\% MMC in teeth treated under an operating microscope. ${ }^{22}$ On the other hand, an in vitro study by Teixeira et al. found no MMC in 50 mandibular molars. ${ }^{23}$ Another study found $22.1 \%$ MMC in Brazilian and $14.8 \%$ in Turkish population. ${ }^{24}$ A systematic review found the overall incidence of MMC to be $2.6 \% .^{5}$ The incidence of MMC in Pakistani population was reported in few in vitro studies only and was $3.3 \%$ in one and $0.8 \%$ in other study. ${ }^{18,19}$ No CBCT study on Pakistani population was reported in literature to our knowledge.

Several factors have been investigated for association with the presence of MMC such as molar type, gender, side of mouth and age. ${ }^{17}$ One study found no difference in distribution of MMC in first versus second molars similar to present study. ${ }^{22}$ Other studies found greater incidence in second molars but the results were not significant. ${ }^{13,25}$ Yet another study found significantly greater number of MMC in first molars. ${ }^{21}$ No difference in the distribution of MMC based on side and gender have been reported, similar to present study. ${ }^{15,22}$ Prevalence of MMC in other studies was higher in younger patients compared to older patients..$^{22,25}$ Present study could not find any significant difference based on age.

Prevalence of isthmus in present study (32.8\%) is less as compared to $64.6 \%$ and $69.6 \%$ found in similar CBCT studies. ${ }^{15,21}$ A Brazilian in vitro study found $33.3 \%$ isthmus in mesial roots of mandibular first molars. ${ }^{23}$ The incidence of isthmus in mandibular molars in Pakistani population was not reported in any study. In the present study, isthmi were significantly greater in 2 nd molars. A similar study found greater number of isthmi in 2nd molars but the difference was not statistically significant. ${ }^{21}$ Females had greater prevalence of isthmi, in present study, while another study reported no difference. ${ }^{15}$ Present study also found the prevalence of isthmus to be greater in younger age and no difference between the two sides, similar to another study. ${ }^{15}$

Additionally, no statistical association was found between the occurrence of an isthmus in the apical third and a MMC in the mesial root, similar to another study.$^{15}$ Although results were not significant, number of canals were generally greater in present study with increasing age which may be attributed to the normal root development process.

There are several practical implications in the endodontic treatment of mandibular molars regarding MMC and isthmus. Detection of these canals might be difficult because their orifice diameter can be up to 3 times less than other canals. ${ }^{24}$ The endodontic access preparation might need modifications to facilitate the detection and negotiation of MMC. Sometimes the orifice may be concealed by the developmental groove joining the MB and ML canals. ${ }^{13}$ The course of the canal may also be complicated as it may join any one of the main canals. ${ }^{17}$ Ultrasonic troughing, magnification, and CBCT have shown to be useful for clinical detection of these canals. ${ }^{13}$ Among these, CBCT carries the risk of radiation, and therefore should be used selectively when conventional radiographs and other simple measures do not enable visualization of root anatomy. ${ }^{26}$ Ultrasonic troughing was required in $22 \%$ of teeth to negotiate MMC in a study. ${ }^{27} \mathrm{~A}$ clinical study conducted in New York, USA found MMC in $46.2 \%$ of teeth after troughing under microscope. ${ }^{25}$ Another study found that although 77\% MMCs could be detected after usual endodontic access, troughing was required for accessing 15\% MMCs whose orifices were 1 to $2 \mathrm{~mm}$ deeper than the cemento-enamel junction. The remaining $7.5 \%$ MMCs whose orifices were more than $2 \mathrm{~mm}$ deep were not negotiable even after troughing. ${ }^{27}$ On the other hand, MMC were found in only $6.6 \%$ teeth after conventional endodontic access, while further $39.6 \%$ teeth were found to have MMC after troughing. ${ }^{25}$ Although emphasis has been placed on the 
detection of MMCs, no specific preparation technique has been proposed in literature. ${ }^{28}$

Due to the common occurrence of isthmi, it has been recommended to routinely use ultrasonic agitation and other advanced irrigation techniques during preparation of mesial roots of mandibular molars. Negative pressure irrigation has been shown to achieve greater debris removal than other irrigation protocols. ${ }^{29}$ Similarly, careful attention to the detection, preparation and retrograde filling is necessary during surgical endodontics of mesial roots of mandibular molars. ${ }^{15}$

The limitations of this study are that the population studied might not be representative since it was a single center study, and the CBCT images were of limited resolution.

\section{CONCLUSIONS}

MMC and isthmi in mesial roots of mandibular molars are not unusual findings in our population. CBCT can be a valuable tool for their detection.

\section{CONFLICT OF INTEREST}

None declared

\section{REFERENCES}

1. Song M, Kim H-C, Lee W, Kim E. Analysis of the cause of failure in nonsurgical endodontic treatment by microscopic inspection during endodontic microsurgery. J Endod. 2011;37:1516-19.

https://doi.org/10.1016/j.joen.2011.06.032

2. Karabucak B, Bunes A, Chehoud C, Kohli MR, Setzer F. Prevalence of apical periodontitis in endodontically treated premolars and molars with untreated canal: a cone-beam computed tomography study. J Endod. 2016;42:538-41.

https://doi.org/10.1016/j.joen.2015.12.026

3. Versiani M, Alves F, Andrade-Junior C, Marceliano-Alves M, Provenzano J, Rôças I, et al. Micro-CT evaluation of the efficacy of hard-tissue removal from the root canal and isthmus area by positive and negative pressure irrigation systems. Int Endod J. 2016;49:107987.

https://doi.org/10.1111/iej.12559

4. Grover C, Shetty N. Methods to study root canal morphology: a review. Endod Pract Today. 2012;6:171-82.

5. de Pablo ÓV, Estevez R, Sánchez MP, Heilborn C, Cohenca N. Root anatomy and canal configuration of the permanent mandibular first molar: a systematic review. J Endod. 2010;36:1919-31. https://doi.org/10.1016/j.joen.2010.08.055

6. Michetti J, Maret D, Mallet JP, Diemer F. Validation of cone beam computed tomography as a tool to explore root canal anatomy. J Endod. 2010;36:1187-90.

https://doi.org/10.1016/j.joen.2010.03.029

7. Fayad MI, Nair M, Levin MD, Benavides E, Rubinstein RA, Barghan $\mathrm{S}$, et al. AAE and AAOMR joint position statement: use of cone beam computed tomography in endodontics 2015 update. Oral Surgery, Oral Medicine, Oral Pathology and Oral Radiology. 2015;120:508-12. https://doi.org/10.1016/j.oooo.2015.07.033

8. Krug R, Connert T, Beinicke A, Soliman S, Schubert A, Kiefner P, et al. When and how do endodontic specialists use cone-beam computed tomography? Australian Endod J. 2019 Feb 8.

https://doi.org/10.1111/aej.12337

9. Setzer FC, Hinckley N, Kohli MR, Karabucak B. A survey of conebeam computed tomographic use among endodontic practitioners in the united states. J Endod. 2017;43:699-704.

https://doi.org/10.1016/j.joen.2016.12.021

10. Mota de Almeida FJ, Knutsson K, Flygare L. The impact of cone beam computed tomography on the choice of endodontic diagnosis. Int Endod J. 2015;48:564-72.

https://doi.org/10.1111/iej.12350

11. Al-Salehi SK, Horner K. Impact of cone beam computed tomography (CBCT) on diagnostic thinking in endodontics of posterior teeth: a before- after study. J Dent. 2016;53:57-63.

https://doi.org/10.1016/j.jdent.2016.07.012

12. Yousuf W, Khan M, Mehdi H. Endodontic Procedural Errors: Frequency, Type of Error, and the Most Frequently Treated Tooth. Int J Dent. 2015;2015:1-7.

https://doi.org/10.1155/2015/673914

13. Chavda S, Garg S. Advanced methods for identification of middle mesial canal in mandibular molars: An in vitro study. Endodontol. 2016;28:92-6.

https://doi.org/10.4103/0970-7212.195425

14. Matherne RP, Angelopoulos C, Kulild JC, Tira D. Use of conebeam computed tomography to identify root canal systems in vitro. J Endod. 2008;34:87-9.

https://doi.org/10.1016/j.joen.2007.10.016

15. Hu X, Huang Z, Huang Z, Lei L, Cui M, Zhang X. Presence of isthmi in mandibular mesial roots and associated factors: an in vivo analysis. Surg Radiolo Anat. 2019;41:815-22. https://doi.org/10.1007/s00276-019-02231-w

16. Baugh D, Wallace J. Middle mesial canal of the mandibular first molar: a case report and literature review. J Endod. 200430:185-86. https://doi.org/10.1097/00004770-200403000-00015

17. Bansal R, Hegde S, Astekar M. Morphology and prevalence of middle canals in the mandibular molars: A systematic review. J Oral Maxillofac Pathol. 2018;22:216-26.

https://doi.org/10.4103/jomfp.JOMFP_194_17

18. Wasti F, Shearer AC, Wilson NH. Root canal systems of the 
Rehman UA/ Siddique SN/ Rehman S/ Munawar M/ Ginai HA

mandibular and maxillary first permanent molar teeth of south asian Pakistanis. Int Endod J. 2001;34:263-6. https://doi.org/10.1046/j.1365-2591.2001.00377.x

19. Faraz SA, Tariq A, Jameel A. Root canal morphology of mandibular first permanent molars - Karachi sample. Pak Oral Dent J. 2015;35: 294-98.

20. Adnan S. Endodontic management of elusive middle mesial canal in mandibular second molar. J Pak Dent Assoc. 2017;26:137-40. https://doi.org/10.25301/JPDA.263.137

21. Tahmasbi M, Jalali P, Nair MK, Barghan S, Nair UP. Prevalence of middle mesial canals and isthmi in the mesial root of mandibular molars: an in vivo cone-beam computed tomographic study. J Endod. 2017;43:1080-83.

https://doi.org/10.1016/j.joen.2017.02.008

22. Nosrat A, Deschenes RJ, Tordik PA, Hicks ML, Fouad AF. Middle mesial canals in mandibular molars: incidence and related factors. $\mathrm{J}$ Endod. 2015;41:28-32.

https://doi.org/10.1016/j.joen.2014.08.004

23. Teixeira F, Sano C, Gomes B, Zaia A, Ferraz C, Souza-Filho F. A preliminary in vitro study of the incidence and position of the root canal isthmus in maxillary and mandibular first molars. Int Endod J. 2003;36:276-80.

https://doi.org/10.1046/j.1365-2591.2003.00638.x

24. Versiani MA, Ordinola-Zapata R, Keles A, Alcin H, Bramante
Middle mesial canals and isthmi in mandibular molars using CBCT

CM, Pecora JD, et al. Middle mesial canals in mandibular first molars: a micro-CT study in different populations. Archives of Oral Biology. 2016;61:130-37.

https://doi.org/10.1016/j.archoralbio.2015.10.020

25. Azim AA, Deutsch AS, Solomon CS. Prevalence of middle mesial canals in mandibular molars after guided troughing under high magnification: an in vivo investigation. J Endod. 2015;41:164-68. https://doi.org/10.1016/j.joen.2014.09.013

26. Patel S, Durack C, Abella F, Shemesh H, Roig M, Lemberg K. Cone beam computed tomography in endodontics: a review. Int Endod J. 2015;48:3-15.

https://doi.org/10.1111/iej.12270

27. Keles A, Keskin C. Detectability of middle mesial root canal orifices by troughing technique in mandibular molars: a micro-computed tomographic study. J Endod. 2017;43:1329-31.

https://doi.org/10.1016/j.joen.2017.03.021

28. Nagmode PS, Patel AV, Satpute AB, Gupta PL. Endodontic management of mandibular first molars with mid mesial canal: a case series. J Con Dent. 2017;2:137-40.

https://doi.org/10.4103/0972-0707.212246

29. Susin L, Liu Y, Yoon J, Parente J, Loushine R, Ricucci D, et al. Canal and isthmus debridement efficacies of two irrigant agitation techniques in a closed system. Int Endod J. 2010;43:1077-90. https://doi.org/10.1111/j.1365-2591.2010.01778.x 